\title{
Lateralized Sensitivity of Motor Memories to the Kinematics of the Opposite Arm Reveals Functional Specialization during Bimanual Actions
}

\author{
Atsushi Yokoi, ${ }^{1,2,3}$ Masaya Hirashima, ${ }^{1}$ and ${ }^{\circledR}$ Daichi Nozaki ${ }^{1}$ \\ ${ }^{1}$ Division of Physical and Health Education, Graduate School of Education, The University of Tokyo, Bunkyo-ku, Tokyo 113-0033, Japan, ${ }^{2}$ Japan Society for \\ the Promotion of Science, Chiyoda-ku, Tokyo 102-8471, Japan, and ${ }^{3}$ Institute of Cognitive Neuroscience, University College London, London WC1N 3AR, \\ United Kingdom
}

It is generally believed that the dominant arm exhibits greater functional advantages over the nondominant arm in every respect, including muscular strength and movement accuracy. Recent studies have proposed that this laterality is due to different underlying control strategies for each limb rather than different limb capabilities constraining performance. However, the functional role and mechanisms of these different control strategies have yet to be elucidated. Here, we report a specialized function of the nondominant arm that plays a significant role only during bimanual movements. Right-handed human participants performed bimanual reaching movements while only one arm was subjected to a force field. Consistent with our previous study, adaptation to the force field decreased gradually as the movement direction of the opposite arm deviated from the trained direction. We also observed that the decrement of the adaptation was significantly greater for the nondominant left arm. According to our previously proposed theory, this poorer generalization of the left arm originated from a difference in parameters characterizing motor memory; the nondominant arm's motor memory was more strongly influenced by the opposite arm's kinematics. Remarkably, a model incorporating this lateralized memory predicted that the nondominant arm would demonstrate greater adaptability to force fields associated with the opposite arm's movement. We confirmed this prediction experimentally and found that this advantage of the left arm disappeared in left-handed human participants. We concluded that the secondary supporting role often played by the nondominant arm in bimanual actions reflects its specialization rather than its inferiority.

\section{Introduction}

Since Broca's classical finding that language ability is accomplished by the function of the left hemisphere, it has been well recognized that functional laterality exists in the human brain. Within the motor system, lateralization manifests as a greater ability in the dominant right arm with respect to muscular force, dexterity, and accuracy of visually guided movement (Woodworth, 1899; Annett, 1985; Elliott and Roy, 1996; Armstrong and Oldham, 1999; Duff and Sainburg, 2007). Popular belief about the absolute inferiority of the nondominant arm has led numerous societies to associate the left hand with weakness, evil, or negativity (Wilson, 1891; Beidelman, 1961; Needham, 1967).

\footnotetext{
Received June 24, 2013; revised May 16, 2014; accepted May 22, 2014.

Author contributions: A.Y. and D.N. designed research; A.Y. performed research; M.H. contributed unpublished reagents/analytic tools; A.Y., M.H., and D.N. analyzed data; A.Y., M.H., and D.N. wrote the paper.

This research was supported by the NEXT Program (Grant\#LSO34 to D.N.) and the Japan Society for the Promotion of Science (Grant-in-Aid for Scientific Research \#26242062 to D.N. and Fellowship to A.Y.). We thank J. Diedrichsen, N. Hagura, and P. Zatka-Haas for helpful comments and suggestions and the members of the Nozaki laboratory, especially Kanae Abe, for professional assistance.

The authors declare no competing financial interests.

Correspondence should be addressed to either of the following: Daichi Nozaki, PhD, Graduate School of Education, The University of Tokyo, 7-3-1 Hongo, Bunkyo-ku, Tokyo 113-0033, Japan, E-mail: nozaki@p.u-tokyo.ac.jp; or Atsushi Yokoi, PhD, Institute of Cognitive Neuroscience, University College London, Alexandra House, 17 Queen Square, London WC1N 3AR, United Kingdom, E-mail: a.yokoi@ucl.ac.uk.

DOI:10.1523/JNEUROSCI.2694-13.2014

Copyright $\odot 2014$ the authors $\quad 0270-6474 / 14 / 349141-11 \$ 15.00 / 0$
}

However, several recent studies have focused on the lateralized function of each arm instead of emphasizing the superiority of the dominant arm. For example, Sainburg et al. (2010)) have demonstrated that the dominant arm has a more specialized ability to control limb dynamics, whereas the nondominant arm is more specialized for the control of limb impedance. They suggested that such lateralized ability might be the foundation of a possible supporting role of the nondominant arm in bimanual actions (Guiard, 1987; Johansson et al., 2006). In their study, however, the superiority of the left arm was shown only within the context of unimanual movements. If laterality is actually related to bimanual movement control, we speculate that the lateralized ability of each arm, if any, would be more visible during bimanual movements.

When performing bimanual actions, the movement of one limb may exert mechanical influence over the opposite limb. The ability to compensate for the mechanical influence of the opposite arm is especially required for its supporting role during bimanual action, even if the arm is stationary (e.g., opening a jar) or moving (e.g., using an ice hockey stick). We have proposed a possible mechanism in which the controller for each arm learns the influence of each of the elements of motor learning (i.e., motor primitives) that encode not only the movement of the relevant arm, but also that of the opposite arm in a multiplicative manner (Yokoi et al., 2011). Considering that the nondominant 
Table 1. Basic statistics of participants

\begin{tabular}{|c|c|c|c|c|c|c|c|c|c|}
\hline \multirow[b]{2}{*}{ Trained arm } & \multicolumn{3}{|c|}{ Experiment $1(n=32)$} & \multicolumn{3}{|c|}{ Experiment $2(n=20)$} & \multicolumn{3}{|c|}{ Experiment $3(n=12)$} \\
\hline & Age & Sex & LQ & Age & Sex & LQ & Age & Sex & LQ \\
\hline Left & $22.4(2.6)$ & M9;F7 & $86.9(10.8)$ & $21.8(1.0)$ & M 7;F3 & $92.8(8.3)$ & $23.2(2.5)$ & M 5; F1 & $-66.4(26.4)$ \\
\hline Right & $24.0(3.7)$ & $\mathrm{M} 9 ; \mathrm{F} 7$ & $85.0(21.1)$ & $23.1(1.4)$ & M 7;F3 & $91.0(10.8)$ & $21.5(1.4)$ & M 5; F1 & $-70.9(33.4)$ \\
\hline & NS & NS & NS & NS & NS & NS & NS & NS & NS \\
\hline
\end{tabular}

Wilcoxon rank-sum tests were performed on the age and LQ data, which are shown as mean (SD). A Fisher's exact test was performed on the sex data (M, male; $F$, female). NS, No significant difference ( $p>0.05$ ) between the left-arm-trained and right-arm-trained groups. Note that the number of participants in Experiment 1 includes both 16 participants tested in our previous work (Yokoi et al., 2011) and a newly recruited group of 16 participants (the data from the other 9 participants, which were not used for the analysis, are excluded from this table).

A
Target
Visual cursor
Starting position

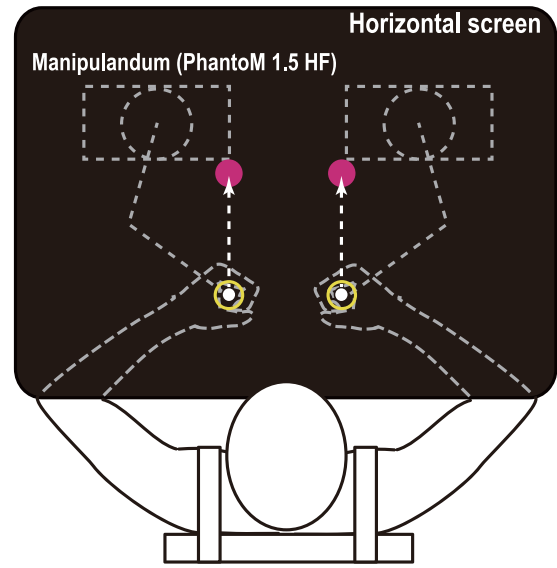

B

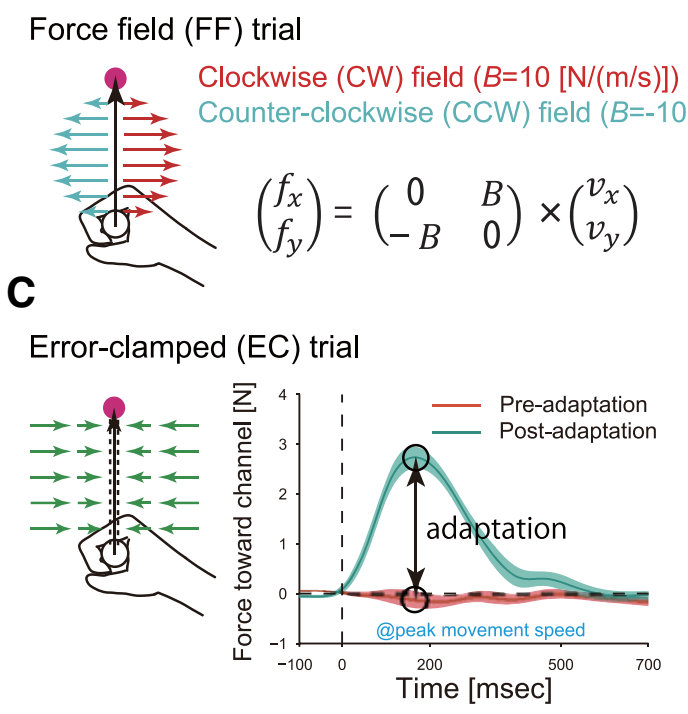

Figure 1. Experimental setting. $A$, The participants were instructed to make center-out reaching movements while holding the handles of two robotic manipulanda. The position of each handle was visualized as a white cursor on a horizontal screen over the participants' arms. The movement of each handle was constrained to a virtual horizontal plane by a simulated spring. The participants wore a wrist brace on each hand and the upper arms were supported by slings. The trunk of each participant was strapped to a chair. $\boldsymbol{B}$, Velocity-dependent force fields were generated by the manipulanda. The force is represented as $\boldsymbol{f}=\boldsymbol{B} \boldsymbol{v}$, where $\boldsymbol{f}=\left(f_{x^{\prime}} f_{\mathrm{y}}\right)^{t}(\mathrm{~N})$ is the force to the handle, $\boldsymbol{v}=\left(v_{x^{\prime}}, v_{y}\right)^{t}(\mathrm{~m} / \mathrm{s})$ is the velocity of the handle, and $\boldsymbol{B}[\mathrm{N} /(\mathrm{m} / \mathrm{s})]$ is the viscosity matrix. For $(W$ force fields, $\boldsymbol{B}=[0-10 ; 100]$ and, for CCW force fields, $\boldsymbol{B}=[010 ;-100]$. C, We used the error-clamp method to quantify motor adaptation. During error-clamped trials, the trajectory of the handle was constrained to a straight line toward the target by a virtual channel in which any motion perpendicular to the target direction was constrained by a one-dimensional spring. This method enabled us to measure directly the lateral force exerted toward the channel. An aftereffect was defined as the difference between the pretraining and posttraining data measured at peak movement speed.

arm more often plays a supporting role during bimanual action, we predicted that laterality would manifest as a difference in how the motor primitives encode the kinematics of the opposite arm.

Therefore, we investigated whether there was a difference between the arms in the dependence of primitives on the opposite arm's direction of movement. To this end, we examined the generalization function describing how the adaptation of one arm to a force field was generalized when the movement direction of the opposite arm was changed from the trained direction. Assuming that adaptation to a novel dynamic environment is accomplished by the flexible combination of the primitives, the generalization function reflects how the primitives encode the kinematics of the limb (Thoroughman and Shadmehr, 2000; Donchin et al., 2003; Yokoi et al., 2011).

\section{Materials and Methods}

\section{Participants}

A total of 45 healthy right-handed subjects ( 31 males and 14 females) and 12 left-handed subjects (10 males and 2 females) participated in this study after providing informed written consent. All experimental procedures were approved by the ethics committee of the Graduate School of Education, The University of Tokyo. Basic information [age, sex, and Laterality Quotient (LQ)] of the participants for each experiment is summarized in Table 1.

\section{General task settings}

The participants were instructed to make center-out reaching movements (amplitude: $10 \mathrm{~cm}$, duration: $400 \mathrm{~ms}$ ) both bimanually and unimanually while holding the handles of two robotic manipulanda (Phantom 1.5 HF; Geomagic; Fig. 1A). The position of each handle was visualized as a white cursor (diameter, $6 \mathrm{~mm}$ ) on a horizontal screen that was placed over the participants' arms so that they could not see their arms directly. The movements of the handles were constrained to a virtual horizontal plane by a simulated spring $(1.0 \mathrm{kN} / \mathrm{m})$ and dumper $[0.1$ $\mathrm{N} /(\mathrm{m} / \mathrm{s})$ ]. To reduce unwanted movement components, the participants wore a wrist brace on each hand and the trunk was strapped to the chair. To reduce fatigue and to allow the maintenance of a constant arm posture, the upper arms were supported by slings.

Task flow. Initially, the participants were instructed to move each cursor into its starting position (diameter, $0 \mathrm{~mm}$; distance between the starting positions for both arms, $16 \mathrm{~cm}$ ). After a $2 \mathrm{~s} \mathrm{holding} \mathrm{time,} \mathrm{a} \mathrm{gray} \mathrm{target}$ (diameter, $10 \mathrm{~mm}$ ) appeared for each hand peripherally $(10 \mathrm{~cm})$ from each starting position. In the unimanual trial, only one target appeared and the participants were instructed not to move the handle for the nontarget side. After a further random holding time (1-2 s), the "go" cue was provided as a color change of the target. A warning message was presented on the screen if the movement speed of either handle was above ("Fast") or below ("Slow") a target range (399.5-540.5 mm/s). At the end of each trial, the handle of each manipulandum automatically returned to its starting position. 
Force field. In each experiment, velocity-dependent force fields were generated by manipulanda (Fig. $1 B$ ). The force is represented as $\boldsymbol{f}=\boldsymbol{B} \boldsymbol{v}$, where $\boldsymbol{f}$ $=\left(f_{\mathrm{x}}, f_{\mathrm{y}}\right)^{t}$ (in Newtons) is the force to the handle, $\boldsymbol{v}=\left(v_{\mathrm{x}}, v_{\mathrm{y}}\right)^{t}$ (in meters per second) is the velocity of the handle, and $\mathbf{B}[\mathrm{N} /(\mathrm{m} / \mathrm{s})]$ is the viscosity matrix. For a clockwise (CW) force field, $\boldsymbol{B}$ $=[0-10 ; 100]$ and, for a counter-clockwise (CCW) force field,

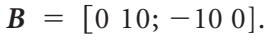

Error clamping. To quantify motor adaptation, we used the errorclamp method (Scheidt et al., 2000; Smith et al., 2006; Sing et al., 2009). During error-clamped trials, the trajectory of the handle was constrained to a straight line toward the target by a virtual channel (Fig. 1C) in which any motion perpendicular to the target direction was constrained by a one-dimensional spring $(2.5 \mathrm{kN} / \mathrm{m})$ and damper $[25 \mathrm{~N} /(\mathrm{m} / \mathrm{s})]$. This method enabled us to measure directly the lateral force that was exerted against the channel. Postexperimental interviews confirmed that only 1 of the 57 participants was aware of the presence of the channel during the experiment (Experiment 1). The data from this participant were excluded from the analysis.

\section{Experiment 1}

The purpose of Experiment 1 was twofold. First, we aimed to examine laterality in the generalization of motor learning. We investigated how motor learning that was acquired while moving both arms forward was transferred when the movement direction of the opposite arm was changed. We have already investigated such transfer in a previous study (Yokoi et al., 2011), but the movement directions of the opposite arm in which the aftereffect was examined were too sparse to obtain the complete profile of motor generalization function. Because we did not measure the degree of adaptation (i.e., force output during error-clamp trial) during the adaptation phase in our previous study (Yokoi et al., 2011), the second purpose of this experiment was to determine whether there is lateralized ability in adaptation to a single force field, as reported by previous unimanual reaching studies (Duff and Sainburg, 2007; Schabowsky et al., 2007). The participants $(n=25)$ were divided into 2 groups according to the arm used for training as follows: Group 1, right arm, $n=12$ (9 males and 3 females) and Group 2, left arm, $n=13$ (8 males and 5 females). The experiment consisted of 135 trials for the baseline session, 100 trials for the training session, and 90 trials for the generalization session.

Baseline session. The participants began by performing bimanual movements under a null force-field condition. The target for the trained arm was always presented at the forward position (i.e., $0^{\circ}$ ) and that for the untrained opposite arm was presented pseudorandomly at 1 of 8 different positions $\left(0^{\circ}, 45^{\circ}, \ldots 315^{\circ}\right.$; Fig. $\left.2 A\right)$. Before the baseline session, the participants performed 90 trials for practice. The error-clamped trials were also randomly interleaved once in three trials to obtain the lateral force against the channel for the baseline condition.

Training session. A CW (or CCW for half of the subjects) force field was imposed on one of the arms while the opposite arm was not subjected to the force field. The participants learned to move both cursors forward toward the targets simultaneously (i.e., the targets for both arms were always presented at $0^{\circ}$; Fig. $2 A$ ). To evaluate how motor learning developed with the training, error-clamped trials were randomly interleaved once in five trials to quantify the lateral force against the channel.

Generalization session. The participants continued the training while moving both arms forward. Error-clamped trials were interleaved in every other trial to quantify how the lateral force against the wall was influenced by the movement direction of the opposite arm. Therefore, in the error-clamped trials, the target for the untrained arm was presented pseudorandomly at 1 of 8 positions $\left(0^{\circ}, 45^{\circ}, \ldots 315^{\circ}\right.$; Fig. $\left.2 A\right)$.

To make a precise evaluation of the generalization of learning, we discarded the data from subjects who did not attain at least $80 \%$ adaptation to the imposed force field (one-sample $t$ test on the last 10 errorclamped trials). We also excluded the data of the participant who was aware of the presence of the force channel during the error-clamp trials. As a result, nine subjects were excluded from the analysis and 16 of 25 subjects remained for further analysis (eight participants for each group). In Group 1, five participants learned the CW force field; in Group 2, four participants learned the CW force field.

\section{A $\operatorname{Exp} 1$}

Trained movement Tested movement

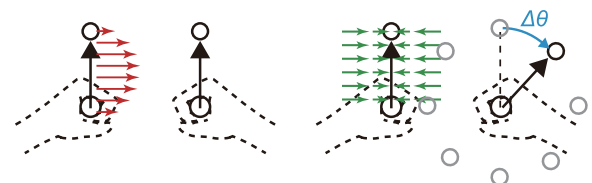

B $\operatorname{Exp} 2 \& 3$

Trained \& Tested movements

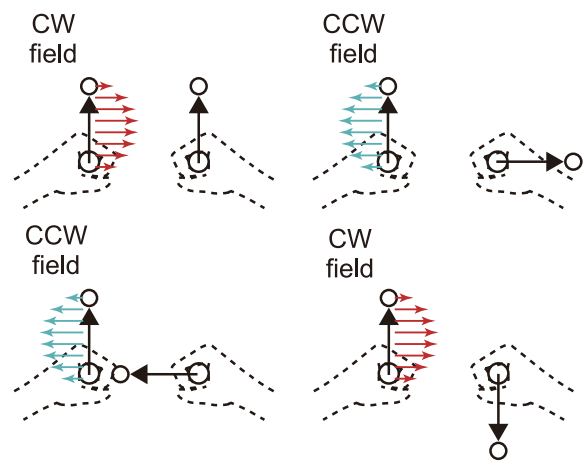

Figure 2. Experimental procedure. A, Experiment 1: Subjects adapted to a force field (FF; either (W or (CW) that was applied to either the left or the right arm while making forward reaching movements with both arms. The generalization was then assessed with the errorclamped trial while changing the movement direction of the unperturbed arm. Note that the illustrated case shows learning CW FF with the left arm. $\boldsymbol{B}$, Experiments 2 and 3 : The direction of the $\mathrm{FF}$ to the perturbed arm was changed depending on the movement direction of the unperturbed arm (CW or $\mathrm{CCW}$ ). The perturbed arm reached in the same direction throughout the experiment. The case of the left-arm-learning group (Group 1) is illustrated.

\section{Experiments 2 and 3}

It has been widely accepted that adapting the identical movements to two conflicting force fields environment (e.g., CW and CCW force fields) is quite difficult (Gandolfo et al., 1996; Osu et al., 2004; Shadmehr et al., 2005) because the motor memory of each force fields overwrites the other through a phenomenon termed interference. However, recent studies have shown that this interference is dramatically reduced when each force field is associated with a different behavioral context, such as the motion of the opposite arm (Nozaki et al., 2006; Howard et al., 2010; Yokoi et al., 2011), orientation of a visual object (Ingram et al., 2010), planned movement direction (Hirashima and Nozaki, 2012a), etc. Our previous simulation study also demonstrated that the degree of motor learning to conflicting force fields might reflect the property of how the motor memory is influenced by the presence of the opposite arm's movement (Nozaki and Scott, 2009).

As shown in the Results section, the results of Experiment 1 demonstrated the presence of laterality in the generalization pattern of motor learning showing how the movement direction of the opposite arm influenced the motor memory. Therefore, we expected that the laterality should be also reflected as the different performance of motor learning to the conflicting force fields, each of which is associated with the unique movement direction of the opposite arm. Experiments 2 and 3 were designed to examine the possibility of lateralized motor learning ability by exposing the same forward reaches of the left/right arm to conflicting (CW or CCW) force fields that were associated with different movement directions of the opposite arm. To see the difference in the ability between right and left arms clearly, we set out to make the task reasonably difficult by using the simulation described in Equations 1-3 (see also Results): the directions of the force field were set to be switched every time the movement direction of the opposite arm was changed by $90^{\circ}$; for example, $0^{\circ}$ : CW, $90^{\circ}$ : CCW; $180^{\circ}$ : CW, $270^{\circ}$ : CCW; Fig. $2 B$ ). 
The experiment consisted of 340 trials: 60 trials for the baseline session, followed by 280 trials for the training session. In both sessions, each of the four movement directions $\left(0^{\circ}, 90^{\circ}, 180^{\circ}\right.$, and $\left.270^{\circ}\right)$ for the opposite arm was performed once within each cycle in a random order. Therefore, 15 trials of each movement were performed during the baseline session and 70 trials were performed during the training session. Notably, the movement direction of the trained arm was kept constant $\left(0^{\circ}\right.$; forward movement). To evaluate the degree of motor adaptation, the errorclamped trials were randomly interleaved in 1 of 3 trials for the baseline session (i.e., 5 trials for each movement direction) and 1 of 7 trials for the training session (i.e., 10 trials for each movement direction).

Twenty participants were divided into two groups $(n=10$ for each group; Experiment 2). For Group 1 ( 7 males and 3 females), training was performed with the left arm while the subjects in Group 2 (7 males and 3 females) learned the force field with the right arm. The association between the force field direction and the movement direction during the training session was reversed for half of the subjects in each group; that is: $0^{\circ}$ : CCW, $90^{\circ}$ : CW; $180^{\circ}$ : CCW, $270^{\circ}$ : CW.

The same task that was described in Experiment 2 was performed by left-handed participants ( $n=12$; Experiment 3$)$. Half of the participants ( 5 males and 1 female) were assigned to the left-arm-learning group. The rest ( 5 males and 1 female) were assigned to the right-arm-learning group.

\section{Data analysis}

All of the data shown are baseline-subtracted values. The motion data for each manipulandum were recorded at a sampling rate of $500 \mathrm{~Hz}$. The data for the handle velocity and force were low-pass filtered with a fourth-order Butterworth filter with a cutoff frequency of $8 \mathrm{~Hz}$. For the index of adaptation, we calculated the learned viscosity coefficient, which was the lateral force, $f$, during the error-clamped trial that was measured at the time $t_{p v}$ of peak movement velocity, $v$, divided by the velocity as follows: $\hat{B}=f\left(t_{p v}\right) / v\left(t_{p v}\right)[\mathrm{N} /(\mathrm{m} / \mathrm{s})]$. The deviation of this value from that measured in the baseline sessions was defined as an aftereffect. The performance of the trials in which the error-clamp method was not adopted (e.g., trials in the training session) was evaluated by the lateral deviation of each handle trajectory from a straight line between the starting position and the target that was measured at the peak movement velocity. The data were then averaged across the participants for each experiment. The sign of the aftereffect from those who adapted to the CCW force field was flipped before averaging.

\section{Statistics}

We applied either a Wilcoxon rank-sum test or a Fisher's exact test on the basic data (age, LQ, and sex) of the subjects whose data were used for the subsequent analysis. For Experiment 1, a two-way mixed-model ANOVA with group (Group 1 and Group 2) as a between-subject factor and epoch (baseline, early, middle, and late) as a within-subject factor was performed on the aftereffect data. An epoch was defined as the average values of the first to fifth (baseline), the sixth and seventh (early), the ninth and $10^{\text {th }}$ (mid), and the $21^{\text {st }}$ to $25^{\text {th }}$ (late) data of the errorclamped trials. For Experiments 2 and 3, two-sample $t$ tests were performed on the aftereffect data that were averaged across the last five error-clamped trials. Effect size (Choen's $d$ ) was also calculated. For the two-sample $t$ tests, if the variances of two groups were significantly different (by $F$ test), a Greenhouse-Geisser correction was applied to adjust for the appropriate degrees of freedom. Two-way mixed-model ANOVAs with group as a between-subject factor and movement direction of the opposite arm as a within-subject factor were also performed on the aftereffect data. As the movements were performed with different arms between the groups, movement direction was defined in the intrinsic coordinate (e.g., rightward movement of the right arm and leftward movement of the left arm were compared). All statistical tests were performed using MATLAB (The MathWorks). Mixed-model ANOVAs were performed by treating subjects as a random effect and nesting them into groups using the anovan function of the statistics toolbox. The type III sum of squares was used for the ANOVA. For Fisher's exact test, we used the fexact function (http://www.mathworks.com/matlabcentral/ fileexchange/22550-fisher-s-exact-test). The significance level was set at $p<0.05$.

\section{Parameter estimation and simulation}

It has been demonstrated that the generalization of motor learning with respect to the changes in the movement pattern provides information about how the neural elements of motor learning (i.e., motor primitives) encodes the movement pattern (Krakauer et al., 2000; Thoroughman and Shadmehr, 2000; Donchin et al., 2003; Tanaka et al., 2009). The concept of motor primitives also enables us to make generative predictions about learning behavior, such as the trial-by-trial changes in the movement error for reaching movements to multiple targets (Thoroughman and Shadmehr, 2000; Donchin et al., 2003), the speed of adaptation to the velocity/position-dependent force fields (Sing et al., 2009), and adaptation to the force fields that depends nonlinearly on the movement direction of both arms (Yokoi et al., 2011). To determine how motor primitives encode the movement directions of the opposite arm with respect to laterality and how laterality influenced the motor learning performance, we estimated the parameters of motor primitives from the generalization function based on several assumptions detailed in the following section.

State-space model. The force output of the internal model, $\hat{f}$, at the $i$-th trial was assumed to be represented by a linear combination of the activity of primitives (Donchin et al., 2003; Gonzalez Castro et al., 2011; Yokoi et al., 2011) as follows:

$$
\hat{f}^{(i)}=\left[\boldsymbol{w}^{(i)}\right]^{t} \boldsymbol{g}\left(\theta^{(i)}\right)
$$

where $\theta$ is the movement direction of the "opposite" arm and $\boldsymbol{g}(\theta)$ $=\left[g_{1}(\theta), g_{2}(\theta), \ldots, g_{N}(\theta)\right]^{t}$ and $\boldsymbol{w}=\left[w_{1}, w_{2}, \ldots, w_{N}\right]^{t}$ are column vectors with elements that represent the output and weight, respectively, of each primitive. Here, $\boldsymbol{g}(\theta)$ should be a function of the movement directions, not only of the opposite arm, but also of the trained arm. However, we considered only the dependence on the opposite arm because the movement direction of the trained arm was fixed in our experiment.

We assumed that the weighting parameter, $\boldsymbol{w}$, was updated with the trials according to the movement error, $e$. This process can be represented as the state-space model as follows:

$$
\begin{gathered}
e^{(i)}=d\left(f^{(i)}-\hat{f}^{(i)}\right) \\
\boldsymbol{w}^{(i+1)}=\alpha \boldsymbol{w}^{(i)}+e^{(i)} K \boldsymbol{g}\left(\theta^{(i)}\right)
\end{gathered}
$$

where $f$ is the imposed force field, $d$ is the compliance of the trained arm, and $\alpha$ and $K$ are constants representing the spontaneous loss of memory and the learning rate, respectively.

Estimation of the parameters for the motor primitive. After sufficient training with the movement direction, $\theta$, of the opposite arm, the force output should reach a plateau level. The generalization function, $\Phi(\Delta \theta)$, is defined as the relative value of the force output when the movement direction of the opposite arm is changed by $\Delta \theta$. We have previously demonstrated that the generalization function can be represented (Yokoi et al., 2011) as follows:

$$
\Phi(\Delta \theta)=\frac{\boldsymbol{g}(\theta)^{t} \boldsymbol{g}(\theta+\Delta \theta)}{\boldsymbol{g}(\theta)^{t} \boldsymbol{g}(\theta)} .
$$

Furthermore, we assumed that each component of $g(\theta)$ is represented by a Gaussian-like function (Donchin et al., 2003; Gonzalez Castro et al., 2011; Ingram et al., 2011; Yokoi et al., 2011; Brayanov et al., 2012) as follows:

$$
g_{j}(\theta)=a \exp \left[-\frac{\left(\theta-\varphi_{j}\right)^{2}}{2 \sigma^{2}}\right]+b,
$$

where $a, b, \sigma$, and $\varphi_{j}$ are the amplitude, offset, tuning width, and the preferred direction (PD), respectively, of the primitives (without loss of generality, we set $b=1-a)$. When the PDs are assumed to be distributed uniformly, the generalization function can be simply represented as follows:

$$
\Phi(\Delta \theta)=A \exp \left\{-\frac{\Delta \theta^{2}}{4 \sigma^{2}}\right\}+B,
$$


Primitives (hidden)

$g_{i}(\theta)=a \exp \left\{-\left(\theta-\varphi_{i}\right)^{2} / 2 \sigma^{2}\right\}+b$

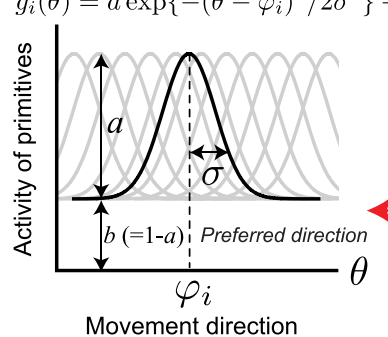

Movement direction

\section{estimate}

\section{Generalization (observable)}

$\hat{f}\left(\theta_{0}+\Delta \theta\right) / \hat{f}\left(\theta_{0}\right)=A \exp \left(-\Delta \theta^{2} / 4 \sigma^{2}\right)+B$

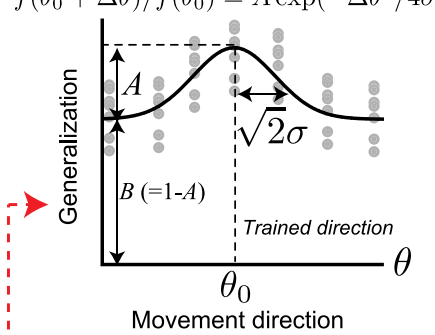

tion (Botev et al., 2010). The probability of overlap between two parameter distributions (i.e., the optimal Bayes error rate; Duda et al., 2001) was calculated based on this estimated density distribution as follows:

$$
\begin{gathered}
P_{\text {overlap }}=\int_{p_{L(a, \sigma)} \leq p_{R(a, \sigma)}} p_{L}(a, \sigma) d a d \sigma \\
+\int_{p_{R(a, \sigma)<p_{L(a, \sigma)}}} p_{R}(a, \sigma) d a d \sigma \\
=\sum_{p_{L}(i, j) \leq p_{R}(i, j)} p_{L}(i, j) \times \Delta a \Delta \sigma \\
+\sum_{p_{R}(i, j)<p_{L}(i, j)} p_{R}(i, j) \times \Delta a \Delta \sigma
\end{gathered}
$$$$
e=d(f-\hat{f})
$$$$
\text { Movement error }
$$$$
\boldsymbol{w}^{(i+1)}=\alpha \boldsymbol{w}^{(i)}+e^{(i)} K \boldsymbol{g}
$$

State-space model

Figure 3. Model framework to estimate the shape of the motor primitives. Structure of state-space model (bottom center; see also Equations $1-3$ ). The force output of the internal model, $\hat{f}$, is represented as the weighted sum of the activity of primitives, $\boldsymbol{g}$. Weight, $\boldsymbol{w}$, is updated trial-by-trial based on the, $e$. Top left, The activity of each primitive, $g_{i}$, was assumed to be a Gaussian-like function (Equation 5). Each primitive has its own PD of opposite arm motion. Note that $\theta$ indicates the movement direction for the opposite arm. We assumed that the $P D$ was uniformly distributed in $\left[0^{\circ}, 360^{\circ}\right]$ space. Top right, Generalization pattern when the movement direction of the opposite arm was changed by $\Delta \theta$ (Equation 6). Under the framework using the state-space model, tuning parameters (i.e., $a, b$, and $\sigma$ ) of the primitives can be estimated from parameters of the generalization pattern (i.e., $A, B$ and $\sqrt{2} \sigma ;$ Equations 7,8$)$.

Table 2. The common parameters used in the simulation

\begin{tabular}{lllll}
\hline$N$ & $\alpha$ & $K$ & $d$ & $j$ \\
\hline 100 & 0.996 & 0.00724 & 8 & Uniform distribution $\left[0^{\circ}, 360^{\circ}\right]$ \\
\hline
\end{tabular}

$$
\begin{aligned}
& A=\frac{a^{2} \sigma}{a^{2} \sigma+2 \sqrt{2} a b \sigma+2 \sqrt{\pi} b^{2}}, \\
& B=\frac{2 \sqrt{2} a b \sigma+2 \sqrt{\pi} b^{2}}{a^{2} \sigma+2 \sqrt{2} a b \sigma+2 \sqrt{\pi} b^{2}} .
\end{aligned}
$$

We fit the generalization data with Equation 6 and then obtained $a, b$, and $\sigma$ with Equations 7 and 8 (Fig. 3). To increase the estimation accuracy, we pooled the data from the current experiment (Experiment 1) and the data from our previously published study (Yokoi et al., 2011; the data in Experiments 1 and 2 were reanalyzed to the same form as that used in the present study).

Calculation of parameter distributions. We estimated the distributions of the parameter sets ( $a$ and $\sigma$ ) by bootstrapping (5000 resamplings). First, Equation 6 was fitted to the pooled data (here, this fitted function is referred to as the estimated model) and the residual vector, the length of which was determined to be $128[72 \times$ (the number of data points obtained in the current experiment) $+56 \times$ (the number of data points obtained in our previous experiment); Yokoi et al., 2011]. Next, 5000 bootstrap residual vectors (length of each vector: 128) were generated by randomly resampling from the original residual vector. Then, 5000 bootstrap datasets were generated by adding the bootstrap residual vectors to the estimated model. By fitting Equation 6 with the 5000 bootstrap datasets, we obtained 5000 bootstrap parameters with Equations 7 and 8. Finally, the density distributions of the parameters were estimated by a two-dimensional kernel density estimation with a MATLAB $k d e 2 d$ func- where $p_{\mathrm{L}}(i, j)$ and $p_{\mathrm{R}}(i, j)$ are the estimated density functions of the parameter distributions for the left and the right arms, respectively, and $\Delta a$ and $\Delta \sigma$ are the estimated band widths for the kernel density estimation.

We also calculated the distribution of the differences in the parameter vectors across the arms with the above bootstrap parameter vectors and estimated the $95 \%$ confidence region of this distribution. The $95 \%$ confidence region was estimated by searching the contour line of the kernel density estimate of the above distribution function, which can exclude exactly $5 \%$ of the data points (i.e., 250 data points; Hall, 1987).

Simulation of motor learning. To quantify the effect of the difference in the parameters for both arms on the adaptation to the force field that was caused by the opposite arm's motion, we simulated Experiment 2 with the state-space model (Equations 1-3) with the 5000 sets of bootstrapped parameters. For the other parameters $(\alpha, d$, and $K$ in Equation 3 ), we used the same values for both arms because we did not observe a significant difference in the initial error between the groups (two-sample $t$ test, $p>0.05$ ) or the amount of learning (two-way ANOVA, see Statistical Analysis section) in Experiment 1. The parameter values are summarized in Table 2.

To mimic Experiment 2, in which 10 participants participated, we first randomly sampled 10 parameter sets from the bootstrapped estimates of the tuning parameters and then simulated Experiment 2 . The simulated learning curves were then averaged across these 10 parameter sets. This process was iterated 1000 times to obtain $95 \%$ confidence intervals of the simulated learning curves.

\section{Results}

\section{Experiment 1}

Previous studies have reported that the dominant arm exhibits a greater ability to adapt to novel dynamics during unimanual reach (Duff and Sainburg, 2007; Schabowsky et al., 2007). However, for the training session in the present study, the trialdependent changes in the aftereffects (i.e., learning curves) were almost indistinguishable between the groups trained with right and left arms (two-way mixed-model ANOVA, no significant main effect of group; $F_{(1,14)}=1.5, p=0.240$; Fig. $4 A$ ). Therefore, we observed no substantial difference between the dominant and nondominant arms in the ability to adapt limb movements to novel dynamics during bimanual reach.

In contrast, we found significant laterality in the generalization of motor learning. The generalization of motor learning was evaluated by changing the movement direction of the untrained 
arm (eight different target directions; Fig. $2 A)$. As was observed in our previous study (Yokoi et al., 2011), the aftereffect for the trained arm decayed as the movement direction of the opposite untrained arm deviated from the original trained direction (Fig. $4 B, C$ ). Notably, the shape of the generalization function, $\Phi(\Delta \theta)$, had different amplitudes between both arms; the amplitude [i.e., $\left\{\Phi\left(0^{\circ}\right)-\Phi\left(180^{\circ}\right)\right\}$ $\times 100]$ was significantly greater for the left arm $(43.7 \pm 15.9 \%)$ than for the right $\operatorname{arm}(28.6 \pm 8.7 \%)\left(t_{(14)}=2.35, p=\right.$ $0.03)$. These results suggested that the motor learning of the nondominant left arm during bimanual movement was more poorly generalized with the change in the dominant right arm's movement direction from the original training direction and, in contrast, the motor learning of the dominant right arm was less affected by the change in the nondominant left arm's movement direction from the original training direction.

The lateralized generalization patterns indicated that how the neural elements for motor learning (i.e., motor primitives) encoded opposite arm motion differed between the right and left arms. Based on our previous study, we estimated the function of the primitives, $g(\theta)$, from the generalization function, $\Phi(\Delta \theta)$, with the theoretical relationship (see Materials and Methods). We began by fitting the data of the generalization pattern with the function $\Phi(\Delta \theta)$ (Equation 6). Then, $a$ and $b$ were obtained from $A, B$, and $\sigma$ with the theoretical relationship between $\Phi(\Delta \theta)$ and $g_{j}(\theta)$ (Equations 7 and 8). In addition, we obtained the distribution of the parameters with bootstrapping.

The distributions of the estimated parameters for each arm were clearly dissociated (Fig. 5). The values of $a$ and $s$ were $0.73 \pm 0.03$ and $37.2 \pm 12.1^{\circ}$, respectively, for the left arm and $0.64 \pm 0.03$ and $45.0 \pm$ $14.0^{\circ}$, respectively, for the right arm (mean \pm SD of the bootstrapping samples). To test the statistical significance of the difference in the two parameter distributions, we calculated the probability of overlap between the two parameter distributions (optimal Bayes error rate) based on the estimated two-dimensional density function (see Materials and Methods), and the value was smaller than 0.05 ( $p=0.037)$. The optimal Bayes error rate is known to give the lower bound for the sum of the Type I and Type II error rates (i.e., $\alpha+\beta$ ) for any hypothesis testing method (Lehmann and Romano, 2005). This means that the two distributions can be theoretically discriminated with up to $95 \%$ accuracy. In addition, we calculated the distribution of the difference in the parameter vectors between the right and left arms from the above bootstrapped distributions. If the parameter vectors are generated from the same distribution, then the $95 \%$ confidence region of the above distribution should contain $(0,0)$. In fact, $(0,0)$ was outside of the $95 \%$ confidence region.

We also need to consider other possible factors for estimating the lateralized features of the primitives. The first possible factor is the influence of the movement accuracy of the opposite arm. As has been reported in several previous studies, the dominant hand shows better movement accuracy than the nondominant hand (Carson et al., 1993; Elliott and Roy, 1996; Mieschke et al., 2001). However, it should be noted that several previous studies have reported movement is more accurate when visual information is

\section{B \\ C}

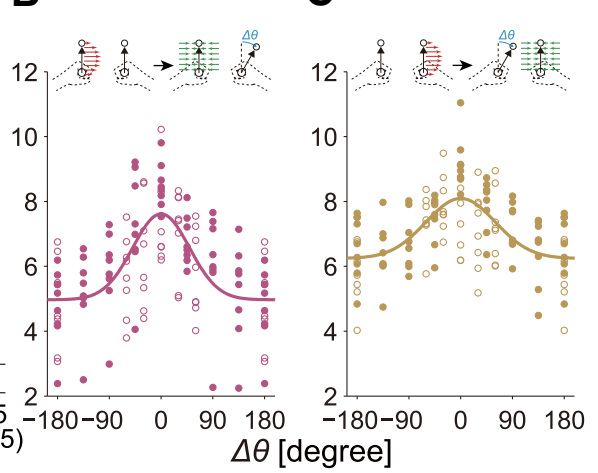

$\Delta \theta[$ degree]

Figure 4. Results of Experiment 1. $\boldsymbol{A}$, Trial-by-trial profile of aftereffects (lateral force at peak movement speed divided by the speed) that were measured in randomly introduced error-clamped trials for baseline and training sessions averaged across subjects (Ex Group 1, C: Group 2) plotted with our previous data (Experiments 1 and 2 in our previously published Yortical axis and the color code are the same as in $A$. These data were fitted with Gaussian functions

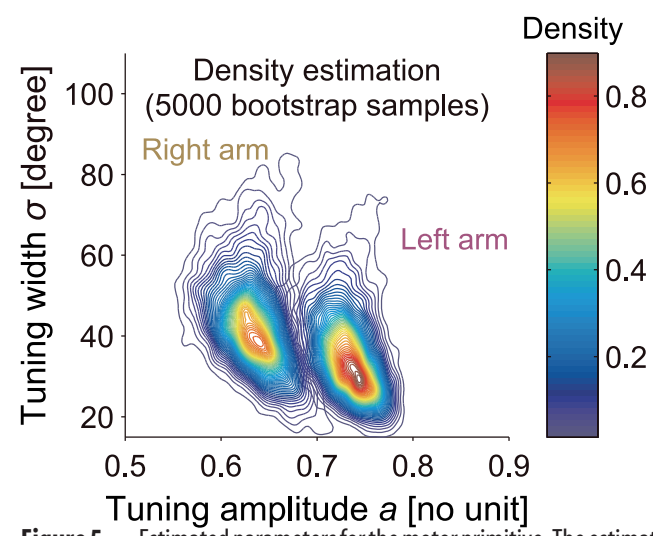

Figure 5. Estimated parameters for the motor primitive. The estimated density distributions of the tuning parameters for the right and the left arms were clearly dissociated from each other. A two-dimensional Gaussian kernel was applied on 5000 bootstrapped estimates of the parameters that were estimated from the generalization data. The color code indicates the density.

unavailable (for review, see Goble and Brown, 2008). Such inaccuracy of the nondominant arm during bimanual reaching might influence the expression of the motor memory that is acquired with the dominant arm in subsequent error-clamped trials in Experiment 1. To test this possibility, we assessed the endpoint accuracy of the opposite arm's movement during error-clamped trials and compared them between the two groups (i.e., training arm was right or left). Two-way mixed-model ANOVAs with the within-subject factor of target direction ( 8 directions, defined by intrinsic coordinates) and the between-subject factor of arm (left or right, i.e., groups) on the endpoint bias (norm of the bias from target position) and variance (trace of covariance matrix) data revealed a significant main effect for target direction $\left(F_{(7,98)}>\right.$ 2.3, $p<0.03)$. However, we did not observe a significant main effect for the arm $\left(F_{(1,14)}<0.75, p>0.40\right)$ or the interaction between the target direction and the arm $\left(F_{(7,98)}<1.14, p>\right.$ $0.34)$.

Another possible factor was a difference in attention load. Reaching with the nondominant arm to different directions may be more demanding than reaching with the dominant arm, which might contribute to the different motor generalization function 
A Shape of primitives $\frac{(0.5,60)}{a}$

B

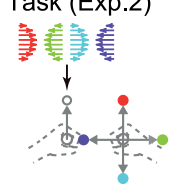

\section{C}

Activation pattern [a.u.]
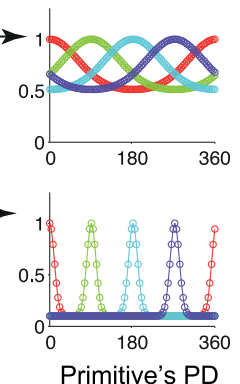

D
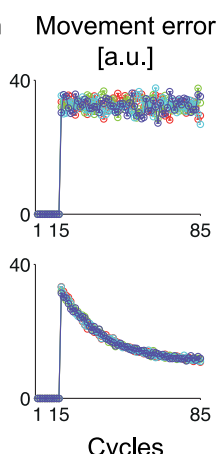

E

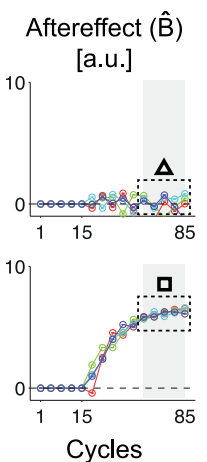

$\mathbf{F}$

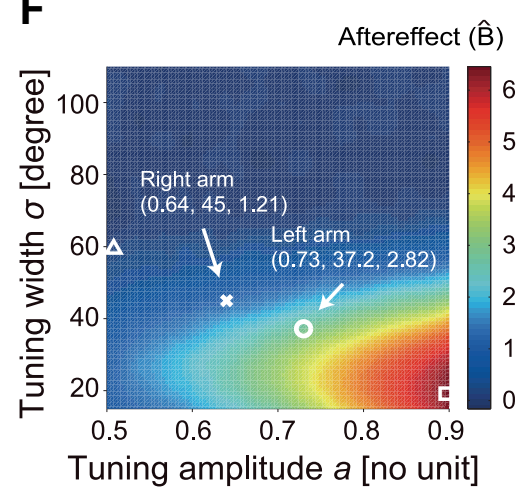

Figure 6. Model prediction of Experiment 2. A, Shapes of two representative primitives from the simulation. $\boldsymbol{B}$, Task setting of Experiment 2. $\boldsymbol{C}$, Activity pattern of primitives. Each point indicates the activity level of each primitive with PD shown in the horizontal axis. Each color indicates the activity pattern corresponding to the movement direction of the opposite arm shown in $\boldsymbol{B}$. $\boldsymbol{D}$, Movement error. $\boldsymbol{E}$, Aftereffect. Note that one cycle consists of four trials. $\boldsymbol{F}$, The color code indicates the amount of the aftereffect averaged across the late phase of motor learning (i.e., the $11^{\text {th }}$ to $15^{\text {th }}$ error-clamped trials indicated by the shaded areas in $\boldsymbol{E}$ ) obtained by simulations with various sets of parameters. Triangle and square indicate the data corresponding to the data shown in $\boldsymbol{E}$.

shown in Figure 4, $B$ and $C$. However, this possibility was unlikely because greater attention load would deteriorate motor learning. Therefore, we would expect to see the opposite of the results observed in Experiment 1 (Fig. 4C): the right arm should have exhibited greater decay than the left arm did because of the greater attention load associated with the motion of the left arm. Therefore, we concluded that the shapes of the primitives' tuning functions were significantly different between the left and the right arms: the primitives for the left arm were more sharply tuned with the opposite arm's movement direction.

\section{Experiment 2}

In the situation that one arm needs to adapt to specific dynamics regardless of what the opposite arm is doing, the broader encoding (and broader generalization pattern) of the opposite arm's motion would be beneficial. However, the broader generalization pattern in turn allows higher interference of motor memories from nearby motion of the opposite arm. Therefore, the same broader encoding pattern turns into a disadvantage when the motor command to the arm needs to be adjusted to various mechanical influences that are strongly associated with the opposite arm's motion. The sharper encoding of the opposite arm's motion therefore could provide the nondominant arm with a beneficial ability to adapt more flexibly to mechanical influences that are caused by the opposite arm's motion during bimanual action. Experiment 2 was designed to test this ability of the nondominant arm so that the one arm was exposed to conflicting force fields, each of which was associated with four different movement directions of the opposite arm (see Materials and Methods; Fig. 2B).

Before performing the experiment, we investigated how the amount of learning depended on the parameters $a$ (tuning amplitude) and $s$ of the primitives (tuning width) of the motor primitives by simulation with a state-space model (Fig. 6; Thoroughman and Shadmehr, 2000; Donchin et al., 2003; Lee and Schweighofer, 2009; Yokoi et al., 2011). When the tuning amplitude is small and the tuning width is wide (Fig. 6A), the movement of the opposite arm in a particular direction activates a greater number of motor primitives simultaneously (Fig. 6C). Because the overlapping motor primitives are exposed to conflicting force fields, this results in greater overlap of the activities that in turn cause greater interference in Experiment 2. As a result, the movement error does not decrease (Fig. 6D) and the aftereffect remains small (Fig. $6 E$ ). In contrast, when the tuning amplitude is large and the tuning width is narrow (Fig. 6A), the activities of the motor primitives are more localized (Fig. 6C), which leads to a decrease in the amount of interference in Experiment 2 (Fig. $6 D, E$ ). Figure $6 F$ demonstrates the whole landscape, showing that the aftereffect (or interference) becomes greater (or smaller) as the tuning amplitude and width become greater and narrower, respectively. Notably, this simulation predicts that the aftereffects should be greater by almost twofold when the left arm was trained versus when the right arm was trained.

Figure 7 shows the changes in the movement error and aftereffect for each of the four movement directions of the opposite arm when the left (Fig $7 A, B$ ) and right arm (Fig 7C,D) were trained. The movement error gradually decreased with the training, whereas the aftereffects gradually increased with the training; however, the rate of the increase in the aftereffect was slower and the final level of the aftereffect was also smaller than observed in Experiment 1 (Fig. 4A) due to interference, as explained schematically in Fig. 6. It should be noted that the value of the aftereffect should be 10 for full adaptation. However, as our computational model predicted (Fig. 6B), we also observed that the participants trained with the left arm exhibited significantly greater aftereffects than those trained with the right arm, because a significant main effect was observed in the averaged aftereffect for the last five error-clamped trials between the groups (two-way mixedmodel ANOVA, $\left.F_{(1,18)}=9.07 ; p=0.0075\right)$, whereas neither a significant main effect for movement direction $\left(F_{(3,54)}=1.65\right.$, $p=0.190)$ nor an interaction between direction and group $\left(F_{(3,54)}=0.10, p=0.955\right)$ was observed.

To compare the aftereffects between both groups and between the predicted aftereffects more directly, the aftereffects were averaged among four different movement directions of the opposite arm (Fig. $8 A, B$ ). Again, the aftereffect (the averaged value of the last five error-clamp trials) of the group trained with left arm was greater than that of the group trained with right arm (onetailed $t$ test, $t_{(16.33)}=3.01, p<0.005$, Cohen's $d=1.42 \pm 8.78$ ). Furthermore, the behavioral data were quite similar to the data predicted by the model with respect to not only the amount of adaptation, but also the trial-dependent change in the learning curve (Fig. 8A). These results indicate that the observed laterality in learning ability between the right and left arms resulted from the laterality of the tuning parameters of the motor primitives. 


\section{Experiment 3}

Experiment 3 was performed to determine whether the superior motor learning ability of the nondominant arm was also observed for left-handed participants. Half of the 12 left-handed participants trained with the dominant left arm and the other half trained with the nondominant right arm. No significant difference was observed when the aftereffect was evaluated separately for the four movement directions (two-way mixed-model ANOVA, $\left.F_{(1,10)}=1.30, p=0.280\right)$. In addition, no significant main effect of movement direction or interaction between movement direction and group was observed $\left(F_{(3,30)}<0.3, p>0.82\right)$, so we averaged the aftereffects among four movement directions. Again, the superior left-handed motor learning that was observed in the right-handed participants disappeared in the left-handed participants and the amount of adaptation did not differ significantly between the groups for the aftereffects averaged across four movement directions of the opposite arm (one-tailed $t$ test, $t_{(10)}=1.258, p=0.119$; Figure $8 C, D)$.
A

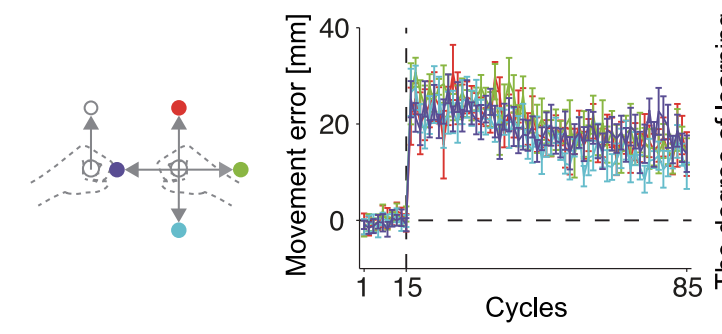

C
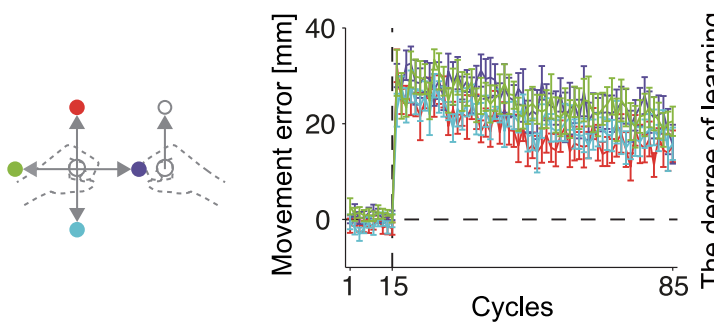

B

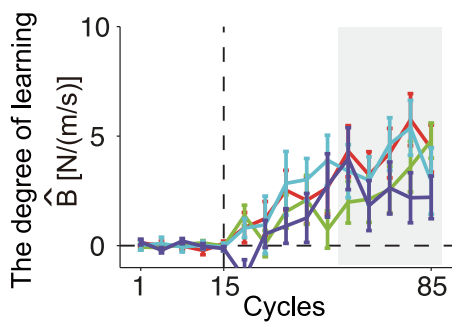

D

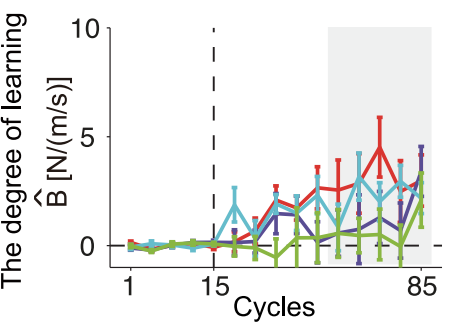

Figure 7. Results of Experiment 2. A, B, Experimental data from the Group 1 (the left arm was trained). $\boldsymbol{A}$, Movement error (lateral hand deviation at peak movement speed) plotted separately for each movement direction of the right arm. Each color corresponds to the movement direction of the opposite arm, as shown in the schematics on the left side of the panel. $\boldsymbol{B}$, Aftereffect measured by error-clamped trials plotted separately for each movement direction of the right arm. Aftereffect data indicated by shaded area $\left(11^{\text {th }}-15^{\text {th }}\right.$ aftereffects) were submitted to subsequent statistical analysis. $C, \boldsymbol{D}$, The same datasets from Group 2 (in which the right arm was trained) presented identically as in $\boldsymbol{A}$ and $\boldsymbol{B}$.

\section{Discussion}

We investigated the possible difference between the dominant and nondominant arms in how motor primitives encode the kinematics of the opposite arm. Experiment 1 demonstrated that adaptation to the force field was influenced more strongly by the changes in the movement direction of the opposite arm for the nondominant arm (Fig. 4B). This poorer motor generalization pattern of the nondominant arm suggests that the primitives of the nondominant arm respond more sensitively to the kinematics of the opposite arm (Fig. 5). Based on this observation, we predicted that this characteristic would provide the nondominant arm with the superior ability to adapt to a dynamic environment that changed in association with the kinematics of the opposite arm (Fig. 6). Experiment 2 confirmed this finding, whereas Experiment 3 demonstrated that the superiority of the left arm disappeared for left-handed participants (Figs. 7, 8).

\section{Lateralized ability and bimanual control}

Previous studies on laterality in motor mechanisms have focused on aspects of unimanual movement control. Sainburg and colleagues have demonstrated that the motor control systems are distinct between the dominant and nondominant arm, stating that the control system of the dominant arm is specialized for the coordination of the dynamics of the arm (trajectory control), whereas that of the nondominant arm is specialized for arm stabilization (endpoint control; Sainburg and Kalakanis, 2000; Bagesteiro and Sainburg, 2002; Duff and Sainburg, 2007; Schaefer et al., 2007; Sainburg, 2010; Mani et al., 2013). The investigators speculated that a control strategy such as this in the nondominant arm contributes to its supporting role during bimanual action, but this idea has not been tested directly.

Even when one limb is used for a supporting role during bimanual action, the ability that is required for the controller does not merely increase the impedance of the limb, but rather gener-
A

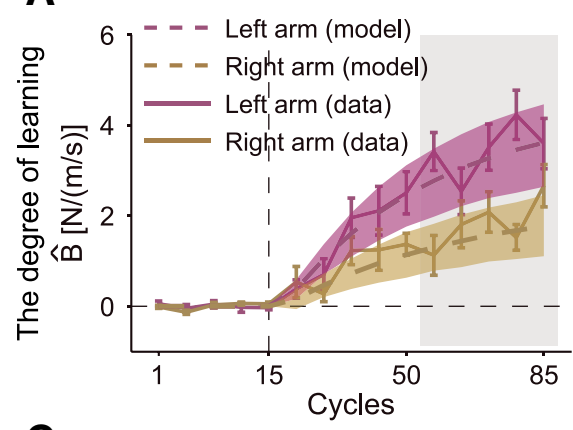

B
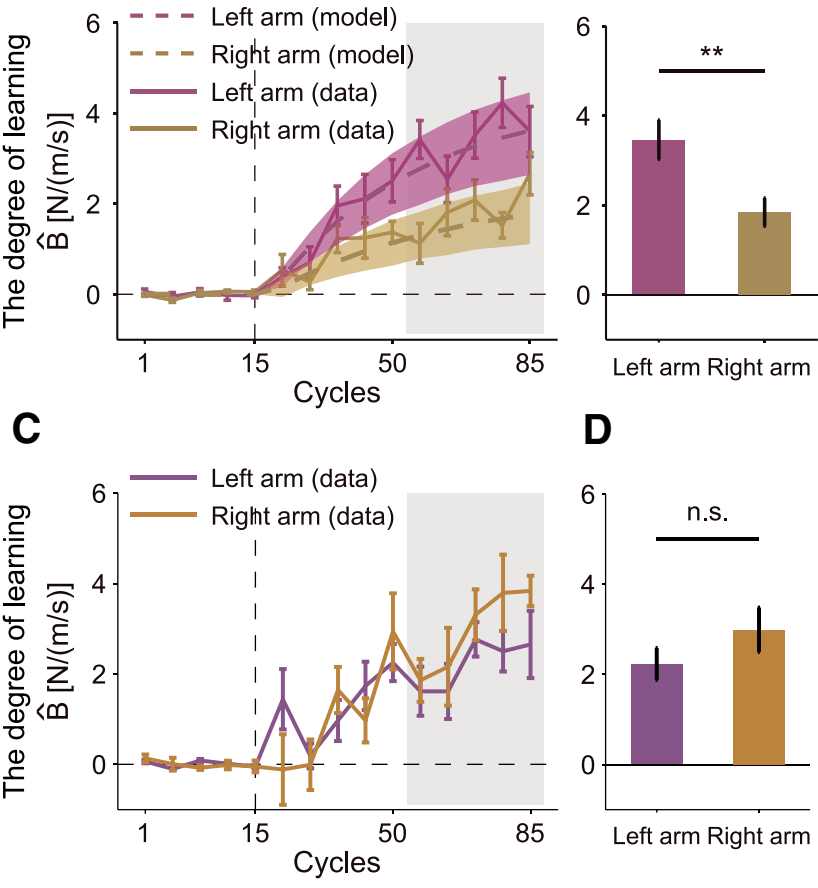

D

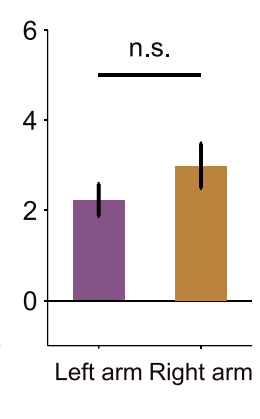

Figure 8. Results of Experiments 2 and 3. A, Learning curve averaged across all movement directions of the unperturbed arm for both groups displayed with the simulated results. The color codes are the same as in Figure 4. Solid lines indicate observed data (mean $\pm \mathrm{SE}$ ); dotted lines, simulated data using the parameter set estimated from the behavioral data; filled areas around dotted lines, $95 \%$ confidence interval for the simulated aftereffects; shaded gray area, data used for subsequent statistical testing $\left(11^{\text {th }}-15^{\text {th }}\right.$ error-clamped trial). $\boldsymbol{B}$, The left arm showed significantly greater amounts of learning $\left({ }^{* *} p<0.005\right)$ than the right arm. The data of the last five error-clamped trials (specified by the shaded gray area in $\boldsymbol{B}$ ) were averaged within each subject. $\boldsymbol{C}, \boldsymbol{D}$, The results for the left-handed participants. The data are displayed in the same manner as in $\boldsymbol{A}$ and $\boldsymbol{B}$. 
ates motor commands to counteract predictively the mechanical influences resulting from the opposite limb (Bays and Wolpert, 2006). Furthermore, bimanual action often involves the movements of both arms, such as hitting a ball with a bat, using a fishing rod, and so on; the nondominant arm is not always stabilized as a fixed endpoint, suggesting that we need to extend the role differentiation problem into more general bimanual movements.

The present study focused on the problem of bimanual action from the viewpoint of how the motor control system could counteract mechanical influences resulting from the opposite arm's movement. We found that the nondominant arm had a superior ability in adjusting motor commands to dynamic environments resulting from opposite arm movement (Figs. 7, 8). This advantage was not apparent in standard motor adaptation experiments (Fig. 4A) in which the arm is imposed on by force fields that are dependent on the arm itself alone (Duff and Sainburg, 2007; Schabowsky et al., 2007; Tcheang et al., 2007). As shown in the present study, this ability only emerged when faced with a complicated force field that varied with the opposite arm's movement (Figs. 7, 8).

\section{Underlying neuronal mechanisms}

Although the neural substrates for the motor primitives are not fully elucidated, neurons in the frontal motor areas, the posterior parietal cortex, and the cerebellum are thought to be involved ( $\mathrm{Li}$ et al., 2001; Della-Maggiore et al., 2004; Padoa-Schioppa et al., 2004; Xiao et al., 2006; Mandelblat-Cerf et al., 2011; Donchin et al., 2012). For example, neurons in the primary motor cortex or premotor cortex that are tuned with the movement direction of the reaching hand (Georgopoulos et al., 1982; Cisek et al., 2003) change their tuning properties after adaptation to a force field ( $\mathrm{Li}$ et al., 2001; Xiao et al., 2006). These neurons also receive neuronal input from the contralateral hemisphere that depends on the kinematics of the opposite arm (Cisek et al., 2003; Rokni et al., 2003; Ganguly et al., 2009). Neurons within the parietal reach region also show activity tuned for bilateral limb movement (Chang and Snyder, 2012). Such interhemispheric neuronal influences have also been reported in humans by using functional magnetic resonance imaging (Diedrichsen et al., 2013).

These findings led us to hypothesize that the motor memory of an arm's movement is formed under neuronal influences arising from the opposite arm's movement in a particular direction. Therefore, this formed motor memory could deteriorate when moving the arm in different directions because the neuronal influences also change. This hypothesis is consistent with the results of our present and previous experiments (Yokoi et al., 2011). From this perspective, the laterality observed in the tuning pattern of the primitives (i.e., tuning amplitude and width) can be interpreted as the difference in the strength of the neuronal influence from the opposite arm, possibly through the corpus callosum (Franz et al., 2000). We suspect that the strength of this influence is greater from the dominant to the nondominant hemisphere rather than vice versa. In fact, it is well known that sensorimotor areas in the dominant hemisphere have greater influence over the nondominant hemisphere in both functional magnetic resonance imaging (Hayashi et al., 2008; Diedrichsen et al., 2013) and electrophysiological studies (Netz et al., 1995; Oda and Moritani, 1995; Ziemann and Hallett, 2001; Duque et al., 2007). Therefore, it is reasonable to suggest that such asymmetrical interhemispheric interactions are a possible neural substrate for the lateralized tuning pattern of the motor primitives.

\section{Is this the specialized ability of the nondominant arm?}

We assume that the present results reflect a specialized ability of the nondominant arm. However, one might argue that our results instead reflect the dominant arm's ability to teach its influence to the opposite arm. One potential experiment to dissect these possibilities would be to use other limbs (e.g., the foot) for testing. If the dominant arm teaches better, then the foot would be expected to adapt to force fields better when the force fields are associated with dominant arm than with nondominant arm. Conversely, if the nondominant arm knows better, the nondominant arm would adapt better to force fields associated with foot motion.

We have already performed a portion of such experiments in which we trained the nondominant left arm with the right foot motion (Nozaki et al., 2006). However, we found that the motor memory for the left arm was not affected by the foot movement, indicating that the nondominant arm is not always adept at considering influence from the other limb's movement. The absence of substantial neuronal interactions within the motor cortex between hand and foot regions (Soteropoulos and Perez, 2011) also supports this notion.

Therefore, the laterality demonstrated in the present study emerges only in the context of bimanual movement control and not in the general context of interlimb movement control. Therefore, it is fundamentally impossible to conclude that the laterality stems either from the greater ability of the dominant arm to teach or the greater ability of nondominant arm to learn (the good math score of students is attributable to both teacher and students). However, regardless of either interpretation, the implication of the present study is not substantially influenced; laterality of the motor primitives leads to functionally different abilities for both arms, which might contribute to their differential roles during bimanual action.

\section{Limitations and conclusions}

Although our computational model predicted the learning behavior in Experiment 2 well, several points need to be addressed in through future studies. First, we assumed the same amplitude and width for all primitives despite the fact that these parameters have a certain extent of variation within individuals (Amirikian and Georgopoulos, 2000). Similarly, we also assumed that PDs of primitive are uniformly distributed, whereas it is known that the distributions are highly skewed (Herter et al., 2007; Hirashima and Nozaki, 2012b). In fact, the degree of adaptation when separately analyzed for each movement direction of the opposite arm in Experiment 2 showed slightly greater adaptation in 0 and 180 than in 90 and 270 (Fig. 7). Although the differences were not significant (see Results), this raises the possibility that the parameters of motor primitives are not homogenous. Further, although a recent study has shown that the forgetting factor, $\alpha$, is context dependent (Ingram et al., 2013), we also assumed a uniform value for all primitives. However, it is notable that the model could capture a substantial difference between the left and the right hands despite its simplicity.

In conclusion, we have demonstrated laterality in both arms' motor primitives with respect to the encoding of the kinematics of the opposite arm, which provided the nondominant arm with functional advantage in learning the mechanical influences resulting from the opposite arm's movements. We speculate that this functional asymmetry of the two arms during bimanual actions contributes to sophisticated bimanual actions by assigning the appropriate functional role for each arm (Guiard, 1987; Stout et al., 2008), although concrete evidence for this is still lacking. 
Furthermore, it remains unknown whether such laterality in the primitive is innate or if it emerges with development. We also do not understand how laterality is modified by extensive training, such as with musical instruments (Schlaug et al., 1995; Fujii et al., 2010). Future comparative studies with both behavioral and physiological approaches may provide further insight into these questions.

\section{References}

Amirikian B, Georgopoulos AP (2000) Directional tuning profiles of motor cortical cells. Neurosci Res 36:73-79. CrossRef Medline

Annett M (1985) Left, right, hand and brain: the right shift theory. Mahwah, NJ: Lawrence Erlbaum Associates.

Armstrong CA, Oldham JA (1999) A comparison of dominant and nondominant hand strengths. J Hand Surg Br 24:421-425. CrossRef Medline

Bagesteiro LB, Sainburg RL (2002) Handedness: dominant arm advantages in control of limb dynamics. J Neurophysiol 88:2408-2421. CrossRef Medline

Bays PM, Wolpert DM (2006) Actions and consequences in bimanual interaction are represented in different coordinate systems. J Neurosci 26: 7121-7126. CrossRef Medline

Beidelman TO (1961) Right and left hand among the Kaguru-a note on symbolic classification. Africa 31:250-257. CrossRef

Botev ZI, Grotowski JF, Kroese DP (2010) Kernel density estimation via diffusion. Ann Stat 38:2916-2957. CrossRef

Brayanov JB, Press DZ, Smith MA (2012) Motor memory is encoded as a gain-field combination of intrinsic and extrinsic action representations. J Neurosci 32:14951-14965. CrossRef Medline

Carson RG, Goodman D, Chua R, Elliott D (1993) Asymmetries in the regulation of visually guided aiming. J Mot Behav 25:21-32. CrossRef Medline

Chang SW, Snyder LH (2012) The representations of reach endpoints in posterior parietal cortex depend on which hand does the reaching. J Neurophysiol 107:2352-2365. CrossRef Medline

Cisek P, Crammond DJ, Kalaska JF (2003) Neural activity in primary motor and dorsal premotor cortex in reaching tasks with the contralateral versus ipsilateral arm. J Neurophysiol 89:922-942. Medline

Della-Maggiore V, Malfait N, Ostry DJ, Paus T (2004) Stimulation of the posterior parietal cortex interferes with arm trajectory adjustments during the learning of new dynamics. J Neurosci 24:9971-9976. CrossRef Medline

Diedrichsen J, Wiestler T, Krakauer JW (2013) Two distinct ipsilateral cortical representations for individuated finger movements. Cereb Cortex 23:1362-1377. CrossRef Medline

Donchin O, Francis JT, Shadmehr R (2003) Quantifying generalization from trial-by-trial behavior of adaptive systems that learn with basis functions: theory and experiments in human motor control. J Neurosci 23: 9032-9045. Medline

Donchin O, Rabe K, Diedrichsen J, Lally N, Schoch B, Gizewski ER, Timmann D (2012) Cerebellar regions involved in adaptation to force field and visuomotor perturbation. J Neurophysiol 107:134-147. CrossRef Medline

Duda RO, Hart PE, Stork DG (2001) Pattern classification: Wiley.

Duff SV, Sainburg RL (2007) Lateralization of motor adaptation reveals independence in control of trajectory and steady-state position. Exp Brain Res 179:551-561. CrossRef Medline

Duque J, Murase N, Celnik P, Hummel F, Harris-Love M, Mazzocchio R, Olivier E, Cohen LG (2007) Intermanual Differences in movementrelated interhemispheric inhibition. J Cogn Neurosci 19:204-213. CrossRef Medline

Elliott DE, Roy EA (1996) Manual asymmetries in motor performance. Boca Raton, FL: CRC.

Franz EA, Waldie KE, Smith MJ (2000) The effect of callosotomy on novel versus familiar bimanual actions: a neural dissociation between controlled and automatic processes? Psychol Sci 11:82-85. CrossRef Medline

Fujii S, Kudo K, Ohtsuki T, Oda S (2010) Intrinsic constraint of asymmetry acting as a control parameter on rapid, rhythmic bimanual coordination: a study of professional drummers and nondrummers. J Neurophysiol 104:2178-2186. CrossRef Medline

Gandolfo F, Mussa-Ivaldi FA, Bizzi E (1996) Motor learning by field approximation. Proc Natl Acad Sci U S A 93:3843-3846. CrossRef Medline
Ganguly K, Secundo L, Ranade G, Orsborn A, Chang EF, Dimitrov DF, Wallis JD, Barbaro NM, Knight RT, Carmena JM (2009) Cortical representation of ipsilateral arm movements in monkey and man. J Neurosci 29: 12948-12956. CrossRef Medline

Georgopoulos AP, Kalaska JF, Caminiti R, Massey JT (1982) On the relations between the direction of two-dimensional arm movements and cell discharge in primate motor cortex. J Neurosci 2:1527-1537. Medline

Goble DJ, Brown SH (2008) The biological and behavioral basis of upper limb asymmetries in sensorimotor performance. Neurosci Biobehav Rev 32:598-610. CrossRef Medline

Gonzalez Castro LN, Monsen CB, Smith MA (2011) The binding of learning to action in motor adaptation. PLoS Comput Biol 7:e1002052. CrossRef Medline

Guiard Y (1987) Asymmetric division of labor in human skilled bimanual action: the kinematic chain as a model. J Mot Behav 19:486-517. CrossRef Medline

Hall P (1987) On the bootstrap and likelihood-based confidence regions. Biometrika 74:481-493. CrossRef

Hayashi MJ, Saito DN, Aramaki Y, Asai T, Fujibayashi Y, Sadato N (2008) Hemispheric asymmetry of frequency-dependent suppression in the ipsilateral primary motor cortex during finger movement: a functional magnetic resonance imaging study. Cereb Cortex 18:2932-2940. CrossRef Medline

Herter TM, Kurtzer I, Cabel DW, Haunts KA, Scott SH (2007) Characterization of torque-related activity in primary motor cortex during a multijoint postural task. J Neurophysiol 97:2887-2899. CrossRef Medline

Hirashima M, Nozaki D (2012a) Distinct motor plans form and retrieve distinct motor memories for physically identical movements. Curr Biol 22:432-436. CrossRef Medline

Hirashima M, Nozaki D (2012b) Learning with slight forgetting optimizes sensorimotor transformation in redundant motor systems. PLoS Comp Biol 8:e1002590. CrossRef Medline

Howard IS, Ingram JN, Wolpert DM (2010) Context-dependent partitioning of motor learning in bimanual movements. J Neurophysiol 104:20822091. CrossRef Medline

Ingram JN, Howard IS, Flanagan JR, Wolpert DM (2010) Multiple graspspecific representations of tool dynamics mediate skillful manipulation. Curr Biol 20:618-623. CrossRef Medline

Ingram JN, Howard IS, Flanagan JR, Wolpert DM (2011) A single-rate context-dependent learning process underlies rapid adaptation to familiar object dynamics. PLoS Comput Biol 7:e1002196. CrossRef Medline

Ingram JN, Flanagan JR, Wolpert DM (2013) Context-dependent decay of motor memories during skill acquisition. Curr Biol 23:1107-1112. CrossRef Medline

Johansson RS, Theorin A, Westling G, Andersson M, Ohki Y, Nyberg L (2006) How a lateralized brain supports symmetrical bimanual tasks. PLoS Biol 4:e158. CrossRef Medline

Krakauer JW, Pine ZM, Ghilardi MF, Ghez C (2000) Learning of visuomotor transformations for vectorial planning of reaching trajectories. J Neurosci 20:8916-8924. Medline

Lee JY, Schweighofer N (2009) Dual adaptation supports a parallel architecture of motor memory. J Neurosci 29:10396-10404. CrossRef Medline

Lehmann EL, Romano JP (2005) Testing Statistical Hypotheses: Springer.

Li CS, Padoa-Schioppa C, Bizzi E (2001) Neuronal correlates of motor performance and motor learning in the primary motor cortex of monkeys adapting to an external force field. Neuron 30:593-607. CrossRef Medline

Mandelblat-Cerf Y, Novick I, Paz R, Link Y, Freeman S, Vaadia E (2011) The neuronal basis of long-term sensorimotor learning. J Neurosci 31:300313. CrossRef Medline

Mani S, Mutha PK, Przybyla A, Haaland KY, Good DC, Sainburg RL (2013) Contralesional motor deficits after unilateral stroke reflect hemispherespecific control mechanisms. Brain 136:1288-1303. CrossRef Medline

Mieschke PE, Elliott D, Helsen WF, Carson RG, Coull JA (2001) Manual asymmetries in the preparation and control of goal-directed movements. Brain Cogn 45:129-140. CrossRef Medline

Needham R (1967) Right and left in Nyoro symbolic classification. Africa 37:425-452. CrossRef

Netz J, Ziemann U, Hömberg V (1995) Hemispheric asymmetry of transcallosal inhibition in man. Exp Brain Res 104:527-533. Medline

Nozaki D, Scott SH (2009) Multi-compartment model can explain partial 
transfer of learning within the same limb between unimanual and bimanual reaching. Exp Brain Res 194:451-463. CrossRef Medline

Nozaki D, Kurtzer I, Scott SH (2006) Limited transfer of learning between unimanual and bimanual skills within the same limb. Nat Neurosci 9:1364-1366. CrossRef Medline

Oda S, Moritani T (1995) Movement-related cortical potentials during handgrip contractions with special reference to force and electromyogram bilateral deficit. Eur J Appl Physiol Occup Physiol 72:1-5. CrossRef Medline

Osu R, Hirai S, Yoshioka T, Kawato M (2004) Random presentation enables subjects to adapt to two opposing forces on the hand. Nat Neurosci 7:111112. CrossRef Medline

Padoa-Schioppa C, Li CS, Bizzi E (2004) Neuronal activity in the supplementary motor area of monkeys adapting to a new dynamic environment. J Neurophysiol 91:449-473. Medline

Rokni U, Steinberg O, Vaadia E, Sompolinsky H (2003) Cortical representation of bimanual movements. J Neurosci 23:11577-11586. Medline

Sainburg RL (2010) Lateralization of goal-directed movement. In: Vision and goal-directed movement, pp 219-288. Champaign, IL: Human Kinetics.

Sainburg RL, Kalakanis D (2000) Differences in control of limb dynamics during dominant and nondominant arm reaching. J Neurophysiol 83: 2661-2675. Medline

Schabowsky CN, Hidler JM, Lum PS (2007) Greater reliance on impedance control in the nondominant arm compared with the dominant arm when adapting to a novel dynamic environment. Exp Brain Res 182:567-577. CrossRef Medline

Schaefer SY, Haaland KY, Sainburg RL (2007) Ipsilesional motor deficits following stroke reflect hemispheric specializations for movement control. Brain 130:2146-2158. CrossRef Medline

Scheidt RA, Reinkensmeyer DJ, Conditt MA, Rymer WZ, Mussa-Ivaldi FA (2000) Persistence of motor adaptation during constrained, multi-joint, arm movements. J Neurophysiol 84:853-862. Medline

Schlaug G, Jäncke L, Huang Y, Staiger JF, Steinmetz H (1995) Increased corpus callosum size in musicians. Neuropsychologia 33:1047-1055. CrossRef Medline

Shadmehr R, Donchin O, Hwang EJ, Hemminger SE, Rao AK (2005) Learn- ing dynamics of reaching. In: Motor cortex in voluntary movements: a distributed system for distributed functions (Riehle A, Vaadia E, eds). pp 297-328. Boca Raton, FL: CRC.

Sing GC, Joiner WM, Nanayakkara T, Brayanov JB, Smith MA (2009) Primitives for motor adaptation reflect correlated neural tuning to position and velocity. Neuron 64:575-589. CrossRef Medline

Smith MA, Ghazizadeh A, Shadmehr R (2006) Interacting adaptive processes with different timescales underlie short-term motor learning. PLoS Biol 4:e179. CrossRef Medline

Soteropoulos DS, Perez MA (2011) Physiological changes underlying bilateral isometric arm voluntary contractions in healthy humans. J Neurophysiol 105:1594-1602. CrossRef Medline

Stout D, Toth N, Schick K, Chaminade T (2008) Neural correlates of Early Stone Age toolmaking: technology, language and cognition in human evolution. Philos Trans R Soc Lond B Biol Sci 363:1939-1949. CrossRef Medline

Tanaka H, Sejnowski TJ, Krakauer JW (2009) Adaptation to visuomotor rotation through interaction between posterior parietal and motor cortical areas. J Neurophysiol 102:2921-2932. CrossRef Medline

Tcheang L, Bays PM, Ingram JN, Wolpert DM (2007) Simultaneous bimanual dynamics are learned without interference. Exp Brain Res 183:17-25. CrossRef Medline

Thoroughman KA, Shadmehr R (2000) Learning of action through adaptive combination of motor primitives. Nature 407:742-747. CrossRef Medline

Wilson D (1891) The right hand: left-handedness. London: MacMillan.

Woodworth RS (1899) The accuracy of voluntary movement. Psychol Rev 3:1-114.

Xiao J, Padoa-Schioppa C, Bizzi E (2006) Neuronal correlates of movement dynamics in the dorsal and ventral premotor area in the monkey. Exp Brain Res 168:106-119. CrossRef Medline

Yokoi A, Hirashima M, Nozaki D (2011) Gain field encoding of the kinematics of both arms in the internal model enables flexible bimanual action. J Neurosci 31:17058-17068. CrossRef Medline

Ziemann U, Hallett M (2001) Hemispheric asymmetry of ipsilateral motor cortex activation during unimanual motor tasks: further evidence for motor dominance. Clin Neurophysiol 112:107-113. CrossRef Medline 